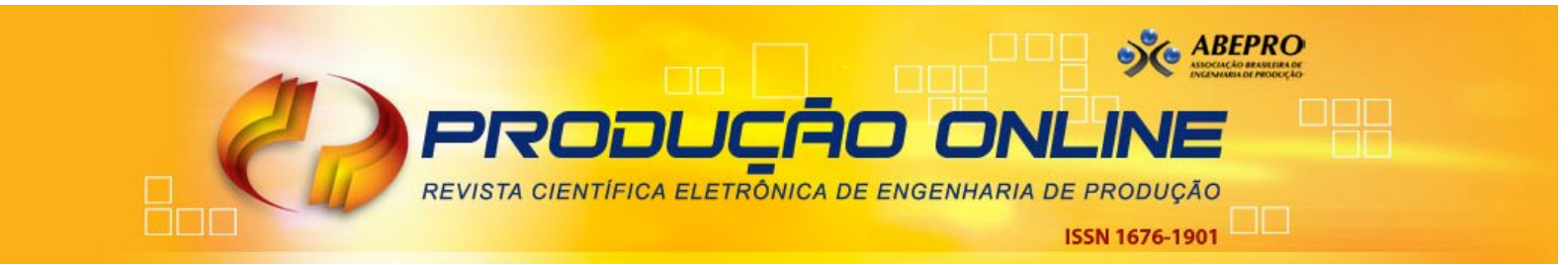

\title{
UMA APLICAÇÃO PRÁTICA DE GESTÃO DO CONHECIMENTO E SIMULAÇÃO NA RESOLUÇÃO DE PROBLEMAS COMPLEXOS EMPRESARIAIS
}

\section{A PRACTICAL APPLICATION OF KNOWLEDGE MANAGEMENT AND SIMULATION IN SOLVING COMPLEX ENTERPRISE PROBLEMS}

\author{
Antonio Carlos Zambon * E-mail: zambon@ft.unicamp.br \\ Gisele Busichia Baioco *E-mail: gisele@ft.unicamp.br \\ Cristiano Chiste ** E-mail: chiste.cristiano@gmail.com \\ Dildre Georgiana Vasques * E-mail: dildre.vasques@gmail.com \\ *Universidade Estadual de Campinas, Faculdade de Tecnologia (UNICAMP), Limeira, SP \\ ** Universidade Estadual de Campinas, Faculdade de Ciências Aplicadas (UNICAMP), Limeira, SP
}

\begin{abstract}
Resumo: Este trabalho apresenta um estudo de caso em uma pequena empresa do setor de máquinas e equipamentos industriais. Essa empresa mostrava problemas relacionados com a incapacidade de entregar as encomendas feitas por seus clientes dentro do prazo acordado, além de diferenças nos métodos de gestão utilizados pelos seus gestores. A fim de analisar e resolver esses problemas, situados na fronteira entre problemas estruturados e não estruturados, inicialmente modelamos o conhecimento dos gestores por meio de diagramas conceituais estendidos apoiados por um processo cognitivo. Posteriormente, simulamos o modelo obtido, usando Dinâmica de Sistemas. O modelo obtido promoveu a aprendizagem em grupo e apoiou estratégias de atendimento por meio de simulação. A modelagem e a simulação desencadearam mudanças no comportamento gerencial e melhoria do clima organizacional. As mudanças comportamentais também resolveram o problema das entregas.
\end{abstract}

Palavras-chave: Tomada de Decisão. Gestão do Conhecimento. Modelagem de Sistemas Complexos. Mapas Conceituais Estendidos. Dinâmica de Sistemas.

Abstract: This paper presents a case study in a small enterprise in the industrial machinery and equipment sector. This enterprise showed problems related to inability to deliver orders placed by its customers within the agreed time, in addition to disagreements between its managers related to management methods. In order to analyze and solve these problems, situated on the border between structured and unstructured problems, we initially modeled manager's knowledge through extended concept diagrams supported by a cognitive process. Then, we simulated the obtained model using System Dynamics. The obtained model promoted group learning and supported service delivery strategies through simulation. Modeling and simulation triggered managerial behavior changes improving organizational climate. These behavioral changes also solved the delivery problem.

Keywords: Decision-making. Knowledge Management. Modeling Complex Systems. Extended Conceptual Maps. System Dynamics.

Revista Produção Online, Florianópolis, SC, v. 16, n. 2, p. 408-440, abr./jun. 2016. 


\section{INTRODUÇÃO}

Segundo dados do Anuário do Trabalho na Micro e Pequena Empresa-2012, no ano de 2011, as Micro e Pequenas Empresas correspondiam a 99\% do total das empresas brasileiras, gerando cerca de $21 \%$ do PIB e $57,2 \%$ dos empregos formais (SEBRAE, 2012).

Esse cenário propicia aos empreendedores diversas oportunidades de crescimento. Porém, as dificuldades encontradas pelas micro e pequenas empresas em acompanhar o ritmo imposto pelo mercado são ainda muito grandes. Isso se deve ao fato da sua competência estar focada, prioritariamente, na produção, em razão de sua reduzida capacidade orçamentária (LUNARDI; DOLCl; MAÇADA, 2010; HILL; JONES; SCHILLING, 2014; TACHIZAWA, 2015). Dessa maneira, tais empresas reduzem investimentos nos processos gerenciais modernos, que se baseiam na informação estratégica e na inteligência. Esse fato gera um déficit competitivo comparado às grandes empresas que possuem orçamentos anuais com valores muito mais expressivos.

Existem diversos fatores que concorrem para o aumento dessa disparidade (GUPTA; HAMMOND, 2005; LUNARDI; DOLCI; MAÇADA, 2010) como, por exemplo, a falta de compreensão dos riscos quanto à ausência de um sistema gerencial adequado e, sobretudo, a baixa prioridade atribuída a esses sistemas pelos dirigentes. Nota-se a ausência de planejamento das pequenas empresas com relação aos investimentos em Tecnologia da Informação e Comunicação (TIC) (LUNARDI; DOLCl; MAÇADA, 2010), desconsiderando o papel fundamental que essas tecnologias exercem na gestão estratégica. Um outro problema encontrado, é a atribuição de cargos de gestão a pessoas de confiança, geralmente da família (MALAQUIAS; ALBERTIN, 2011; CERRATO; PIVA, 2012) que, supostamente, reduziriam as necessidades de investimento em controle, gestão do conhecimento e inteligência.

Essas condições foram constatadas em um estudo de caso realizado em uma empresa do setor de máquinas e equipamentos industriais, considerada de pequeno porte, que atua na região metropolitana de Campinas, interior do Estado de São Paulo. Com 30 funcionários, a empresa apresentou, durante o ano de 2012, problemas relaci-

Revista Produção Online, Florianópolis, SC, v. 16, n. 2, p. 408-440, abr./jun. 2016. 
onados à incapacidade de entrega dos pedidos efetuados por seus clientes dentro do prazo combinado.

O cenário no qual a empresa se insere possui problemas oriundos da ineficiência da gestão da informação e da inteligência corporativa, causada por recursos técnicos insuficientes, que redundam em problemas no sistema de entregas. Tais problemas reduziram a capacidade financeira da empresa e causaram um colapso de gestão.

As atividades de análise participativa desenvolvidas na empresa permitiram identificar falhas no relacionamento entre os diretores, os quais demonstraram incapacidade de conduzir planos táticos conjuntos que culminassem na solução ou mitigação dos problemas enfrentados.

Muitas empresas operam com essa incapacidade de alinhar planos táticos conjuntos e isso se deve, também, ao fato de seus gestores não compartilharem seus modelos mentais (SENGE, 2006; MOSCOSO; FRANSOO; FISCHER, 2010; GENTNER; STEVENS, 2014), causando barreiras para o trabalho em equipe e, consequentemente, o seu desalinhamento (FRANK; ECHEVESTE, 2011).

Senge (2006) estabelece que o desperdício de energia é uma característica fundamental das equipes sem alinhamento. Quando uma equipe se torna mais alinhada, surge uma unicidade de direção na qual as energias dos indivíduos se harmonizam, cessando seu desperdício (OU et al., 2014) e produzindo aprendizagem organizacional (ARGOTE, 2012; GARCÍA-MORALES; JIMÉNEZ-BARRIONUEVO; GUTIÉRREZGUTIÉRREZ, 2012).

O modelo mental compartilhado surge da compreensão mútua dos modelos mentais individuais. Modelos mentais são representações originalmente individuais construídas a partir de experiências pessoais sobre situações reais ou imaginárias, percepções ou compreensões do discurso. Portanto, cada indivíduo cria e evolui constantemente o seu modelo e o utiliza como guia para a aplicação que faz das coisas (JOHNSON-LLAIRD, 2004; GENTNER; STEVENS, 2014).

A falta de integração de modelos mentais consiste em uma falha na gestão do conhecimento e é observada nos processos empresariais quando estes apresentam problemas provocados pelas diferentes abordagens dos gestores (LEVINE; Revista Produção Online, Florianópolis, SC, v. 16, n. 2, p. 408-440, abr./jun. 2016. 
THOMPSON; MESSICK, 2013), culminando em ações isoladas e desintegradas. Como agravante, muitos dos problemas do ambiente corporativo são complexos e se posicionam em uma zona de fronteira, onde as decisões dos agentes humanos devem ser apoiadas por instrumentos analíticos.

A metodologia da Dinâmica de Sistemas (DS), do inglês System Dynamics (FORRESTER, 1980; SENGE, 2006; MORECROFT, 2015) consiste de um meio para resolver problemas presentes nessa fronteira, em razão de sua proposta de utilização do pensamento sistêmico. Entende-se que o pensamento sistêmico (KRAMER; DE SMIT, 2012) representa uma abordagem importante para o entendimento das partes e do todo, gerando aprendizado em grupo e gerindo o conhecimento disperso no ambiente (NORTH, 2010). A DS emprega conceitos de modelagem e simulação matemática, usualmente definidos como abordagem hard, e conceitos de modelagem por meio de diagramas conceituais, de causa e efeito que representam os modelos mentais dos agentes, usualmente denominados como abordagem soft (FORRESTER, 1980; SENGE 2006; FLOOD; CARSON, 2013).

No presente trabalho, descreve-se a proposta de utilização da abordagem soft complementada pela abordagem hard em uma situação de fronteira. $\mathrm{Na}$ abordagem soft, visando apoiar a construção de modelos mentais compartilhados e, consequente, a gestão desse conhecimento, emprega-se a modelagem por meio de mapas conceituais estendidos. Essa modelagem considera que o conhecimento pode ser representado por meio de mapas conceituais contidos em matrizes de atributos (ZAMBON; BAIOCO; MAGRIN, 2012). Observa-se que esse tipo de modelagem favorece a conversão de um modelo soft para um modelo hard simulável, tornando possível ao analista gerenciar uma base de conhecimento e avaliar seu emprego na solução de um problema complexo.

O problema abordado nesta pesquisa se passa em uma pequena empresa familiar, que manifestava problemas com os prazos de entrega de máquinas aos seus clientes. Os gestores atribuíram essa dificuldade às relações entre produção e mercado, ignorando as divergências existentes entre as suas decisões administrativas, provenientes dos seus modelos mentais.

Revista Produção Online, Florianópolis, SC, v. 16, n. 2, p. 408-440, abr./jun. 2016. 
Parte-se do pressuposto de que o emprego de um modelo de solução de problemas apoiado nas abordagens soft e hard, de maneira complementar, possa identificar e revelar a causa dos conflitos entre os diferentes modelos mentais. Acredita-se que o apoio da simulação favoreça a gestão do conhecimento, possibilitando fomentar estratégias conjuntas, demonstrando os resultados que podem emergir de um modelo mental compartilhado.

Em suma, o objetivo deste trabalho foi o emprego de ferramentas de gestão do conhecimento e simulação, em uma pequena empresa, como instrumentos táticos para o auxílio à resolução de problemas de atendimento de pedidos.

O trabalho está organizado em outras 4 seções, além dessa introdução. $\mathrm{Na}$ Seção 2 são apresentados os trabalhos relacionados com a problemática em questão. $\mathrm{Na}$ Seção 3 são discutidas as bases da gestão do conhecimento nas organizações, bem como as diferentes abordagens de resolução de problemas. A Seção 4 relata o estudo de caso, juntamente com a aplicação do processo de representação do conhecimento e a proposta de melhoria por meio da utilização de simulação. Por fim, na Seção 5, são descritas as conclusões sobre a análise realizada.

\section{TRABALHOS RELACIONADOS}

Segundo Cezarino e Beltrán (2009), a formulação da estratégia deve ser abordada como um sistema complexo, que cresce e se modifica, tornando-se visível apenas a longo prazo e, para o qual, portanto, deve-se considerar uma abordagem sistêmica não imediata. Complexidade, nesse contexto, é definida por Haken (2006), por meio da Teoria do Caos e da abordagem sistêmica (BERTALANFFY, 2008), considerando que os sistemas empresariais possuem incontáveis variáveis inter-relacionadas, que são mutáveis em relação ao tempo e por esse motivo provocam incerteza.

Das pesquisas desenvolvidas nesse campo do conhecimento, surgiu a Dinâmica de Sistemas (DS) (FORRESTER, 1980) que, a partir de diagramas de enlaces causais simuláveis por computador, permitiu interpretar a organização empresarial como um sistema complexo (MORECROFT, 2015). Utilizada inicialmente para representar e si- 
mular operações complexas, essa metodologia passou a abranger o processo gerencial superior quando incorporou a possibilidade de representar também os modelos mentais dos agentes em diagramas conceituais, dando origem à abordagem das organizações que aprendem, ou aprendizagem organizacional (SENGE, 2006). A estruturação de problemas por meio de conceitos cognitivos também já havia sido abordada por Checkland (1988), por meio da Soft Systems Methodology (SSM).

Dessa maneira, surgem as abordagens soft (diagramas conceituais) e hard (simulações) da DS. Essas duas abordagens, largamente empregadas no ambiente empresarial, todavia, se mantiveram separadas, considerando a distância entre os campos de utilização.

Rodriguez-Ulloa (2005), no entanto, propôs um modelo de união entre as abordagens soft e hard. Desse modo, o autor, com base no trabalho de Checkland (1988), discute a proximidade entre a DS e a SSM, combinando-as efetivamente e criando a abordagem Soft System Dynamics Methodology (SSDM).

$\mathrm{Na}$ SSDM são resolvidas fragilidades observadas em DS e SSM, por um lado, pela oportunidade de utilização de modelos matemáticos propostos pela DS hard, e por outro, pela heurística para solução de problemas presentes na SSM, que contempla os conceitos cognitivos dos agentes. Portanto, na proposta da SSDM, presume-se uma ampliação da capacidade dos instrumentos que, se utilizados em conjunto, tornam possível uma avaliação mais abrangente de problemas de fronteira bem estruturados e não estruturados.

No entanto, Flood e Jackson (1991) apontam algumas limitações, tanto para a SSM, quanto para a DS soft, particularmente quanto ao risco de analistas procederem a avaliações interpretativas, adicionando conceitos provenientes de seus próprios modelos mentais, em detrimento da preservação da integridade dos modelos mentais dos agentes analisados. Isso ocorre, sobretudo, em razão dos analistas utilizarem inferências para a construção dos modelos.

Além das dificuldades naturais para se realizar uma representação fidedigna de modelos mentais de outros agentes, Beuren, Frank e Ribeiro (2015) reforçam a existência de outros problemas que dificultam a transferência do conhecimento tácito entre os Revista Produção Online, Florianópolis, SC, v. 16, n. 2, p. 408-440, abr./jun. 2016. 
integrantes de uma equipe. Segundo a gestão do conhecimento, interpretar as regras pelas quais tais transferências ocorrem é crucial para a construção sistêmica do ambiente de conhecimento, pois criam uma relação histórica contínua dos agentes com esse ambiente.

A memória é o meio pelo qual fragmentos do conhecimento são arquivados para serem recuperados em momentos oportunos, sob o arbítrio do agente de decisão (BADDELEY, 1992). Sob esse aspecto, Zambon, Baioco e Magrin (2012) propõem um modelo que leva à reprodução de regras mentais utilizadas no processo de recuperação da memória e, por isso, preserva-se a integridade do modelo, que não se utiliza de inferências dos analistas.

Sob essas considerações, este trabalho tem como objetivo ampliar a proposta de Rodriguez-Ulhoa (2005), associando o modelo proposto por Zambon, Baioco e Magrin (2012) a um modelo hard de DS, visando à análise de problemas complexos sob uma abordagem cognitiva.

\section{AS BASES DA GESTÃO DO CONHECIMENTO NAS ORGANIZAÇÕES HUMANAS}

A gestão do conhecimento é um processo corporativo, focado na estratégia empresarial e que envolve a gestão das competências, a gestão do capital intelectual, a aprendizagem organizacional, a inteligência empresarial e a educação corporativa. Segundo Nonaka e Takeuchi (1996), a gestão do conhecimento nas empresas deve ser orientada à criação de um fluxo que permita a conversão do conhecimento tácito para o conhecimento explícito e vice-versa.

Liebowitz e Frank (2010) esclarecem que a gestão do conhecimento tornou-se um processo central na busca e obtenção de inteligência competitiva, em virtude da ampliação do acesso às informações. Entretanto, apenas o acesso à informação não representa ampliação do nível de conhecimento corporativo, que depende também da abordagem sistêmica para relacionar a informação, transformando-a em conhecimento.

Revista Produção Online, Florianópolis, SC, v. 16, n. 2, p. 408-440, abr./jun. 2016. 


\subsection{Abordagem sistêmica e dinâmica de sistemas}

Senge (2006) afirma que as organizações que se lançam à aprendizagem organizacional se deparam com problemas provenientes dos processos de gestão e enfrentam problemas de interpretação sistêmica, provenientes da complexidade das atividades internas e das demandas do ambiente externo.

Pela abordagem sistêmica, o todo representa algo maior do que a soma das partes (BERTALANFFY, 2008), logo, as relações entre os componentes de um sistema adicionam um valor a esse sistema. Esse valor adicionado define como os componentes se relacionam entre si e com o ambiente externo e, também, como as trocas ocorrem em termos de quantidade e velocidade.

A abordagem sistêmica permite uma interpretação ampla do funcionamento das organizações por meio do reconhecimento das relações (estrutura), sendo que dessas relações decorrem os padrões de troca (dinâmica), estando ambos intrinsecamente relacionados. Sob esses argumentos, Forrester (1980) propôs a DS, que se baseia no pressuposto de que a estrutura sistêmica determina o comportamento dinâmico do sistema.

A DS é uma metodologia para modelagem e simulação de sistemas organizacionais, onde a estrutura do sistema, formada pela inter-relação das diferentes partes ou variáveis, é representada por estoques e fluxos. Estoque designa qualquer entidade que acumula ou esgota um valor ao longo do tempo. Fluxo é a taxa que incrementa ou decrementa um estoque. Existem também elementos denominados conversores, que são auxiliares de entrada que atuam nos fluxos.

Na DS, os estoques só podem ter seus níveis alterados por meio de fluxos. Por exemplo, considerando que a quantidade de alguma variável de estoque no tempo I é $\mathrm{Q}(\mathrm{t})$, a derivada de $\mathrm{Q}(\mathrm{t}) / \mathrm{dt}$ é o fluxo de alterações no estoque. Também o estoque em qualquer tempo t é a integral do fluxo para qualquer tempo, de to até tn. Como exemplo, se o estoque de "produtos" $E(t)$ aumenta gradualmente ao longo do tempo por um fluxo de "produção" $P(t)$ e diminui gradualmente ao longo do tempo por um fluxo de "descartes" $D(t)$, então a taxa de variação do estoque de "descarte" é dada pela expressão (1): Revista Produção Online, Florianópolis, SC, v. 16, n. 2, p. 408-440, abr./jun. 2016. 


$$
d E(t) / d t=P(t)-D(t)=P^{n}(t)
$$

Na expressão (1), $P^{n}(t)$ refere-se à diferença entre a produção inicial e os descartes. O tempo $(t)$ em uma simulação é definido pela necessidade de análise considerando que, em escala, um mês simulado pode equivaler a um segundo real, por exemplo.

A simulação atua no sentido de ampliar a capacidade dos agentes de decisão em entender a dinâmica dos sistemas (STERMAN, 2000). Para Humphreys (2013), os gestores tendem a agir de acordo com percepções muito simplificadas da realidade, o que representa um fator de limitação. Sterman (2000) afirma que, caso o agente de decisão não compreenda a dinâmica do sistema empresarial, o sistema irá resistir às tentativas de mudança, frustrando esse agente. Nesse aspecto, a simulação representa um instrumento de aprendizado bastante significativo, pois permite a compreensão dos padrões de comportamento, tornando possível identificar os inter-relacionamentos sistêmicos responsáveis por esses padrões e, consequentemente, os eventos por eles gerados (SENGE, 2006).

Segundo Sterman (2000), situações fortuitas advêm da estrutura de um sistema complexo, que é não-linear, ou seja, é constituído de maneira retroalimentada por incontáveis ciclos. Sendo assim, os processos ocorrem em feedback, onde os resultados das ações definem a situação a ser enfrentada no futuro. Esse conceito de retroalimentação das ações e políticas está presente em todos os sistemas organizacionais, e, desde que o comportamento dinâmico do sistema não seja compreendido, esses problemas de interpretação conduzirão os agentes de decisão a avaliações inadequadas do sistema.

\subsection{Visão compartilhada e aprendizagem organizacional}

A aprendizagem organizacional nasce da ideia básica da criação da visão compartilhada. Isso ocorre porque os processos corporativos passam pela necessidade de atender a vários grupos de interesses e devem contornar problemas de agência.

Revista Produção Online, Florianópolis, SC, v. 16, n. 2, p. 408-440, abr./jun. 2016. 
Os acordos negociados pelos grupos de interesse são efetivados pela compreensão da situação litigante para posteriormente buscar soluções sustentadas. Todavia, em grande parte dos processos de negociação as partes se focam em seus próprios modelos mentais, esquecendo-se de compreender as relações sistêmicas envolvidas no que está sendo negociado (GUASCO; ROBINSON, 2007). Compartilhar uma decisão pressupõe a existência de uma visão abrangente e crítica sobre os próprios modelos mentais e isso se torna possível quando eles são explicitados (NONAKA; TAKEUCHI,1996).

Explicitar significa revelar a estrutura dos modelos mentais de todos os agentes de decisão participantes de um processo de negociação. Essa medida contribui para que todos interpretem a estrutura dos modelos e aprendam uns com os outros, estabelecendo nexos causais e correlacionais entre os eventos que levam ao sucesso ou ao fracasso.

Em suma, a aprendizagem organizacional desenvolve a capacidade de disseminar e favorecer a visão compartilhada e os modelos interpretativos coletivos, buscando a unidade de entendimento dos fenômenos complexos (KIMMERLE et al., 2010) que decorrem da arquitetura dos sistemas organizacionais.

\subsection{Diferentes tipos de abordagem para a resolução de problemas nos sistemas complexos empresariais}

Segundo a DS, a completude da compreensão de um sistema complexo se dá quando a modelagem qualitativa da estrutura do sistema é complementada pela modelagem formal e pela experimentação por meio da simulação por computador (FORRESTER, 1980; MORECROFT; STERMAN, 2000; STERMAN, 2000).

Segundo Sterman (2000), a simulação atua como um filtro por meio do qual os agentes de decisão interagem com o sistema procurando compreender os efeitos das suas decisões, ajustando-as para alinhar o sistema aos seus objetivos (ciclo simples de aprendizagem), além de rever os seus modelos mentais e de redefinir a estratégia e os objetivos (ciclo duplo de aprendizagem).

Revista Produção Online, Florianópolis, SC, v. 16, n. 2, p. 408-440, abr./jun. 2016. 
Geralmente, as abordagens tradicionais de resolução de problemas empresariais, pautadas principalmente em dados históricos e quantitativos (estatísticos), se mostram efetivas à resolução de problemas operacionais e bem estruturados. No entanto, em outras circunstâncias, quando os problemas organizacionais não podem ser solucionados pelas ferramentas já desenvolvidas pelas organizações, é usual a busca por alternativas junto a consultores externos.

Nesse modelo de intervenção, a responsabilidade para a solução do problema usualmente é transferida do agente interno (gerente) para o agente externo (consultor), que escolhe o método de intervenção buscando solucionar o problema de maneira a atender ao agente interno. Essa dinâmica é demonstrada na Figura 1:

Figura 1 - Dinâmica de solução de problemas por consultoria externa

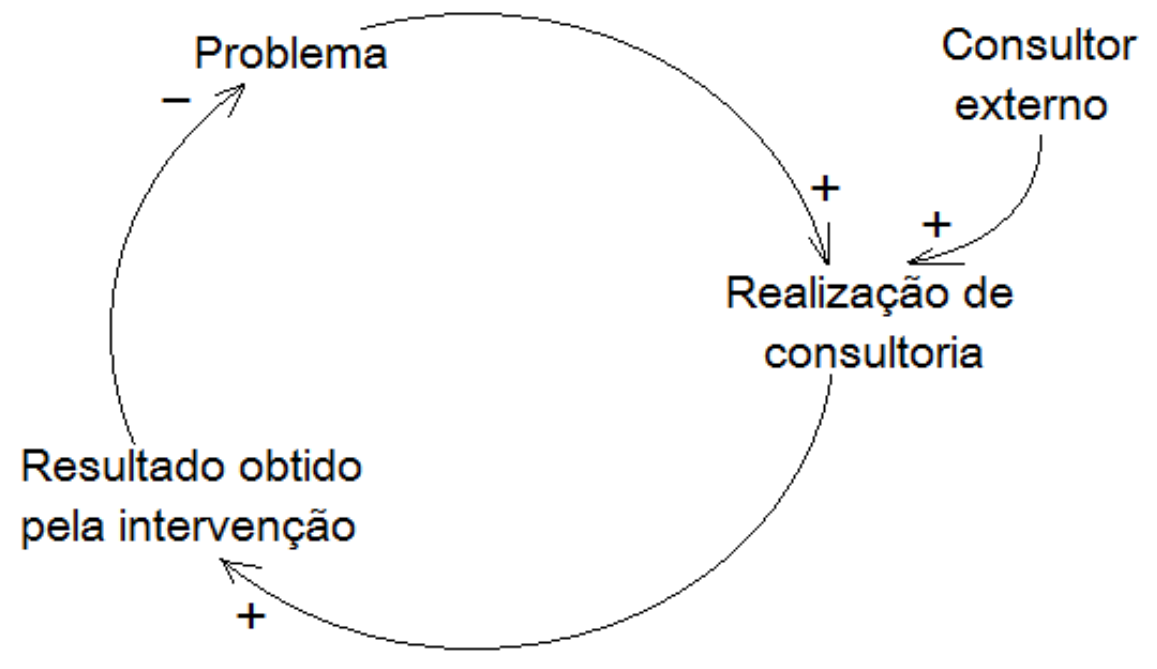

Fonte: Adaptado de SENGE (2006)

A Figura 1 demonstra que um "Problema" influencia a "Realização de consultoria", sob a intervenção do "Consultor externo". Um "Resultado obtido pela intervenção", desde que satisfatório, balanceará o "Problema", reduzindo-o.

Observa-se que a participação do agente externo é que movimenta o ciclo de resolução de problemas, que não é dividido com o agente interno. Nesse ambiente, não há externalização de modelos mentais ou aprendizagem organizacional, posto que recai apenas sobre o agente externo a responsabilidade de solucionar um problema. Enten-

Revista Produção Online, Florianópolis, SC, v. 16, n. 2, p. 408-440, abr./jun. 2016. 
de-se também que o conhecimento construído para a solução do problema não permanecerá na organização, pois pertence ao consultor. Dessa maneira, a prática constante de terceirização de soluções reduz a construção da aprendizagem organizacional e não promove a gestão do conhecimento, pois os modelos mentais não são compartilhados. Sendo os modelos mentais particionados, existe um alto risco das soluções propostas não serem sustentáveis.

De acordo com a abordagem soft da DS, assim como da SSM, a intervenção mais adequada passa pela necessidade de alinhamento dos modelos mentais do consultor e do gestor interno. Apenas dessa maneira torna-se possível identificar quais são as reais demandas internas para, então, buscar soluções sustentáveis aos problemas.

Em pesquisa acerca da estrutura cognitiva da qual emergem os modelos mentais, Zambon, Baioco e Magrin (2012) propõem um modelo de representação do conhecimento baseado em um mapa conceitual, contido em uma matriz de atributo, ou seja, um mapa conceitual estendido. O modelo se baseia na reprodução das regras de recuperação de memória humana e tem como objetivo explicitar o conhecimento de indivíduos por meio de um diagrama conceitual apoiado em uma matriz de atributos. Os conceitos que formam o diagrama estão relacionados em causa e efeito, com pesos de balanceamento e reforço, nos mesmos moldes dos diagramas de feedback da DS soft. Esse diagrama é então posicionado em uma matriz, na qual os conceitos recebem atributos de temporalidade e controlabilidade. O conjunto de conceitos relacionados e atributos é denominado mapa conceitual estendido.

Explicita-se o conhecimento de um agente visando a interpretação de um sistema que contém um problema. Dessa maneira, o modelo parte de uma proposição inicial (P) com a qual se define um problema, que será interpretado sistemicamente a partir do conhecimento extraído de um agente de decisão. Assim, de uma proposição "P" originase uma estrutura de conceitos relacionados e seus atributos, com os quais se pode interpretar profundamente um problema. Um exemplo desse tipo de modelagem é representado na Figura 2.

Revista Produção Online, Florianópolis, SC, v. 16, n. 2, p. 408-440, abr./jun. 2016. 
Figura 2 - Estrutura de um mapa conceitual estendido

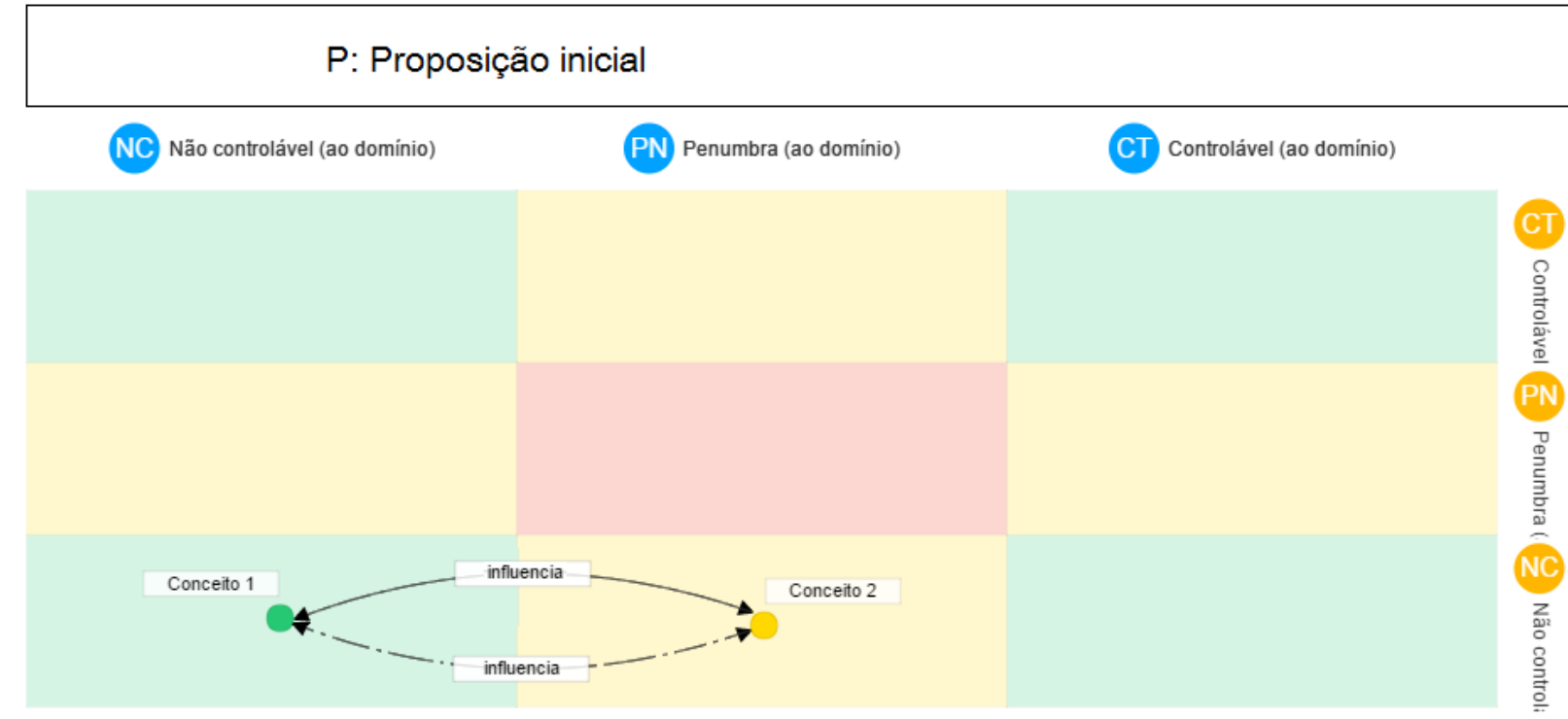

Fonte: Elaborado pelo autores

Na Figura 2, estão dispostos conceitos que explicam ou estendem o conhecimento sobre "P", que se encontra localizado sobre a matriz de atributos. Os conceitos se posicionam na matriz em termos de controlabilidade sobre o cenário de análise (colunas) e em termos de controlabilidade do agente de decisão (linhas).

Tanto na horizontal quanto na vertical, cada conceito se associa com o problema que está sendo analisado em três segmentos que vinculam cada conceito a " $P$ " com uma escala de forças que vai se tornando mais tênue da direita para a esquerda e de cima para baixo, nessa ordem: controlável, penumbra e não controlável (CT, PN e NC).

A relação do agente de decisão com "P" se encontra nas linhas da matriz e reflete a sua capacidade de realizar mudanças no estado dos conceitos estendidos da "P". A relação de cada conceito contido na matriz com "P" se encontra nas colunas e reflete a capacidade de cada conceito em realizar mudanças no estado de "P". Os segmentos classificados como "controlável" possuem atributos de dependência para a realização de mudanças no sistema. Segmentos classificados como "não-controlável" possuem atributos de autonomia quanto às mudanças que impõem no sistema e, segmentos classificados como "penumbra", traduzem a incerteza contida no sistema (ZAMBON; BAIOCO; MAGRIN, 2012).

Revista Produção Online, Florianópolis, SC, v. 16, n. 2, p. 408-440, abr./jun. 2016. 
O relacionamento entre os conceitos e a intensidade desse relacionamento aparece em termos de relações causais, onde a transferência de energia de um conceito sobre outro é dada por um verbo (VASQUES et al., 2016), acrescido de vínculos de reforço ou de balanceamento. O conceito de balanceamento (linha traço-ponto), ocorre quando há uma diferença entre o estado atual e o estado desejado de uma variável, gerando ações a fim de eliminar essa diferença. O conceito de reforço (linha contínua) representa um mecanismo que gera crescimento no sistema. O estado do sistema se desenvolve de maneira contínua, como um efeito "bola de neve". Esse crescimento é representado por uma taxa de mudança.

Em suma, a aplicação prática do modelo começa pela representação do conhecimento do agente (detentor do conhecimento) sobre um problema. O consultor explica as regras para que o agente possa entender como é feita a construção do mapa conceitual estendido. Então, o agente externaliza verbalmente os conceitos relacionados ao problema em questão, atribuindo a cada um o grau de controlabilidade. Depois, são adicionadas as influências entre os conceitos, que são representadas pelas setas $(\rightarrow)$ e verbos. Por fim, são atribuídos os pesos de balanceamento "-" ou de reforço "+" a essas influências. Concluído o processo, obtém-se a estrutura lógica do problema segundo o agente.

O mapa conceitual estendido, por ser orientado pelas mesmas regras dos modelos soft de DS, pode ser convertido em um modelo de simulação (hard).

\section{ESTUDO DE CASO}

Este estudo de caso foi desenvolvido em uma empresa fabricante de máquinas de envase e que se encontrava na situação problemática de incapacidade de realizar a entrega de seu produto aos clientes no prazo combinado. Este é um problema típico pelo qual passam as pequenas empresas que desassociam os investimentos em tecnologias de produção e inteligência de mercado, tornando-se incapazes de construir estratégias de médio e longo prazo.

Revista Produção Online, Florianópolis, SC, v. 16, n. 2, p. 408-440, abr./jun. 2016. 
A empresa em questão é uma empresa familiar, que fabrica máquinas de envase e as vende para fábricas de cosméticos. Possui vinte e oito colaboradores e dois sócios que trabalham em regime integral. Um dos sócios (Agente A) gerencia o departamento de projetos das máquinas, enquanto o outro sócio (Agente B), é o encarregado da produção das máquinas.

$O$ agente $A$ é pai do agente $B$ e ambos possuem formação em engenharia, o que Ihes proporciona um olhar técnico sobre a produção. A relação de hierarquia familiar acaba por impregnar o modelo de gestão empregado por ambos, que não é compartiIhado, sobretudo em situações de crise. Esse problema se reflete no clima organizacional, aumentando o atraso nas entregas. As divergências dos sócios são tácitas, pois se submetem à relação hierárquica. Todavia, emergem na forma de discordâncias entre os sócios (agentes) com relação aos motivos que fazem com que as máquinas produzidas não sejam entregues nos prazos previamente estabelecidos.

Com o objetivo de auxiliar os sócios a desenvolverem o aprendizado organizacional, aplicou-se a técnica de mapa conceitual estendido em conjunto com a simulação em DS para explicitar seus modelos mentais e iniciar um processo de gestão do conhecimento.

\subsection{Aplicação de instrumentos de gestão do conhecimento na análise de proble- mas empresariais}

A interação com a empresa foi realizada em duas fases. A explicitação dos modelos mentais foi realizada na Fase I e permitiu identificar os pontos litigantes existentes entre os agentes. Ela resultou na obtenção dos modelos mentais particionados e possibilitou iniciar a Fase II. Na Fase II foi possível aos agentes comparar seus modelos mentais e negociar pontos litigantes, convergindo para um modelo mental compartilhado, por meio do qual ambos passaram a pensar conjuntamente sobre o problema. Em seguida, a conversão desse modelo mental compartilhado em um modelo simulado permitiu testar as variáveis "imaginadas" pelos agentes, relativamente à lógica e aos possíveis resultados advindos da adoção do modelo de gestão conjunto.

Revista Produção Online, Florianópolis, SC, v. 16, n. 2, p. 408-440, abr./jun. 2016. 
A intervenção, dividida em duas fases, foi desenvolvida por meio dos seus respectivos passos:

Fase I - modelagem por meio de mapas conceituais estendidos:

a. declaração do problema de estudo (P);

b. extração do conhecimento dos agentes por meio de entrevistas;

c. modelagem do conhecimento utilizando um mapa conceitual estendido.

Fase II - modelagem e simulação:

a. conversão do mapa conceitual estendido em um modelo simulável;

b. simulação do modelo obtido.

Com a aplicação desses passos, foi possível realizar a intervenção na empresa, que se deu, inicialmente, a partir de entrevistas não estruturadas com os agentes A e B.

\subsection{Modelagem por meio de mapas conceituais estendidos}

Como primeira providência para a modelagem dos mapas conceituais estendidos dos agentes, definiu-se a pergunta inicial $(P)$, que foi feita para os agentes $A$ e $B$ com o objetivo de se obter as impressões de cada um sobre o problema:

$P$ - Porque as máquinas não são entregues no tempo contratado?

Apoiados pela proposição inicial $(P)$, os sócios declararam suas impressões pessoais sobre o problema, por meio de uma entrevista não estruturada. A entrevista serviu para a externalização de palavras-chave, ou conceitos, para a expansão do significado da P inicial. No centro do significado de cada conceito, há um substantivo e todos os conceitos são relacionados entre si por meio de um verbo, que designa a ação (VASQUES et al., 2016). Os conceitos identificados durante as entrevistas, bem como seus significados estendidos foram os seguintes:

Revista Produção Online, Florianópolis, SC, v. 16, n. 2, p. 408-440, abr./jun. 2016. 
- "Clientes": todos os clientes da empresa;

- "Produção": processo produtivo da empresa. Compreende o projeto da máquina, montagem e entrega;

- "Resultado financeiro": medidos no final do exercício ou de uma série temporal;

- "Retrabalho": qualquer ação para resolver não conformidades;

- "Atrasos no prazo de entrega": tempos de desenho, fabricação, montagem, testes e entrega da máquina;

- "Tempo de atraso": tempo que excede o prazo de entrega;

- "Motivação": espécie de energia psicológica ou tensão que põe em movimento o organismo humano;

- "Clima organizacional": conceitos tácitos de valor, observados no comportamento das pessoas que fazem parte da organização.

Esses conceitos relacionados por meio de um verbo, compõem um mapa conceitual, que é adicionado a uma matriz de atributos, resultando em um mapa conceitual estendido, demonstrado na Figura 3.

Observa-se na Figura 3, que o conceito "Clientes" se encontra em uma região de "Penumbra" horizontalmente e "Controlável" verticalmente. A leitura desse conceito, em especial, identifica que o agente talvez seja capaz de controlar os "Clientes" (PN) porque ele sabe que os pedidos chegam e ele os produz. Sabe também que "Clientes" previamente definidos, não representam problemas para controlar o volume de máquinas a serem entregues (CT). Esses clientes influenciam positivamente na sua "Produção", pois ocorre uma relação de reforço entre os conceitos, ou seja, mais clientes geram mais pedidos e, consequentemente, mais "Produção". 
Figura 3 - Mapa conceitual estendido da situação problemática

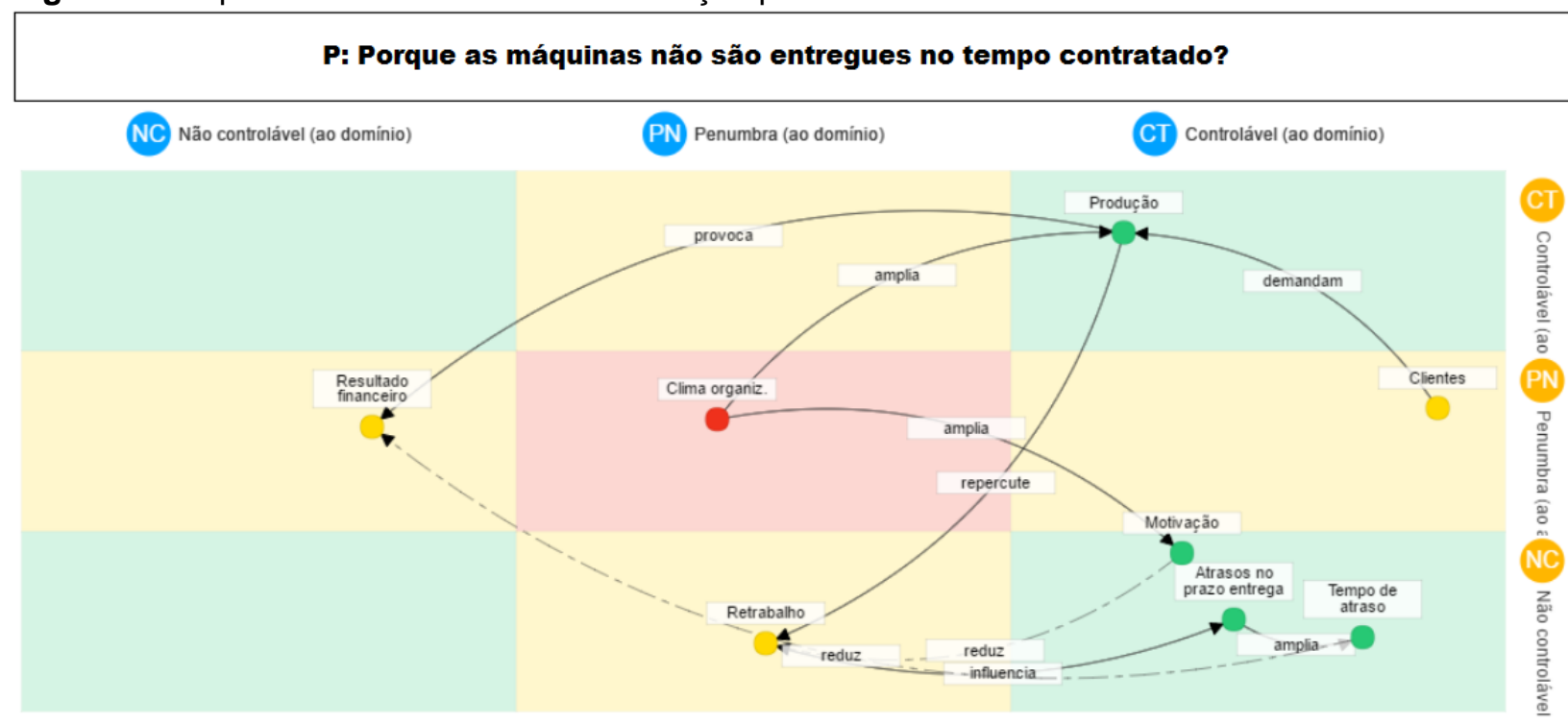

Fonte: Elaborado pelo autores

A "Produção" é algo controlável pelo agente e o "Clima organizacional" a influencia diretamente. Esse "Clima organizacional" é algo que ocorre em uma região de penumbra, logo, não se pode saber precisamente quanto pode ser nocivo ao ambiente. $\mathrm{O}$ "Clima organizacional" influencia a "Motivação" que por sua vez, não é controlável, porém, influencia o ambiente problemático.

Quanto ao "Retrabalho", os agentes sabem que ele ocorre, porém, se o "Clima organizacional" melhorar, o "Retrabalho" será reduzido porque a "Motivação" poderá aumentar. O "Retrabalho", por sua vez, é influenciado pela "Produção" de maneira diretamente proporcional, ou seja, quanto maior a "Produção", maior o "Retrabalho" e, logicamente, quanto mais "Retrabalho", maior serão os "Atrasos no prazo de entrega" e o "Tempo de atraso". Esse problema culmina na diminuição do "Resultado financeiro".

Em virtude do contexto qualitativo, a validação de um mapa conceitual estendido deve ser realizada pelos agentes detentores do conhecimento. Desde que haja concordância entre os agentes A e B, o mapa conceitual estendido representará a arquitetura mental lógica da situação problemática que foi explicitada, tornando-se um instrumento de aprendizado coletivo, bem como uma maneira analítica de se mapear causa e efeito do problema, testando possíveis soluções.

Revista Produção Online, Florianópolis, SC, v. 16, n. 2, p. 408-440, abr./jun. 2016. 
Após validado, o mapa conceitual estendido foi convertido em um modelo de simulação hard, ou seja, em um modelo de estoque e fluxo simulado, para que os agentes pudessem identificar a dinâmica das relações entre os conceitos, verificar sua transformação ao longo do tempo e tomar decisões para a mudança do cenário.

\subsection{Modelagem e simulação}

A conversão do mapa conceitual estendido em um modelo simulado se inicia pela escolha dos conceitos que serão representados como "estoque". Essa escolha dependerá da necessidade de análise, considerando que a característica da variável estoque é demonstrar as mudanças ocorridas no sistema em razão das variações de estado. Neste caso, as variáveis escolhidas foram "Resultado financeiro", "Atrasos no prazo de entrega" e "Clima organizacional", conforme demonstrado na Figura 4.

A Figura 4 demonstra o modelo simulado (ISEE SYSTEMS, 2009) do mapa conceitual estendido dos agentes. Todos os conceitos existentes no mapa conceitual estendido foram representados no diagrama de estoque e fluxo, reproduzindo a estrutura de relacionamentos.

Em termos matemáticos, nessa representação, o estoque "Atrasos no prazo de entrega" tem valor zero, variando a partir das entradas do fluxo "Produção" e "Clima Organizacional", como na expressão:

Atrasos_no_prazo_de_entrega $(t)=A t r a s o s \_n o \_p r a z o \_d e \_e n t r e g a(t-d t)+($ Retrabalho $)$ * $d t$

INIT Atrasos_no_prazo_de_entrega $=0$

\section{INFLOWS:}

Retrabalho = Produção-Motivação

Observa-se que os atrasos no prazo de entrega são inicialmente iguais a zero e sofrem incrementos do fluxo "Retrabalho" ao longo da simulação. O fluxo "Retrabalho", por sua vez, é composto do fluxo de "Produção" decrescido do fluxo "Motivação", que atua reduzindo a quantidade de máquinas produzidas.

Revista Produção Online, Florianópolis, SC, v. 16, n. 2, p. 408-440, abr./jun. 2016. 
O estoque "Clima Organizacional" sofre decrementos de "Motivação". Inicialmente "Clima Organizacional está completo (100\%) e sofre decrementos de 9\% a cada unidade de tempo simulada, como na seguinte expressão:

Clima_Organizacional $(t)=$ Clima_Organizacional $(t-d t)+(-$ Motivação $) * d t$

INIT Clima_Organizacional $=100$

\section{OUTFLOWS:}

Motivação $=9$

Figura 4 - Modelo de Dinâmica de Sistemas elaborado a partir do mapa conceitual estendido

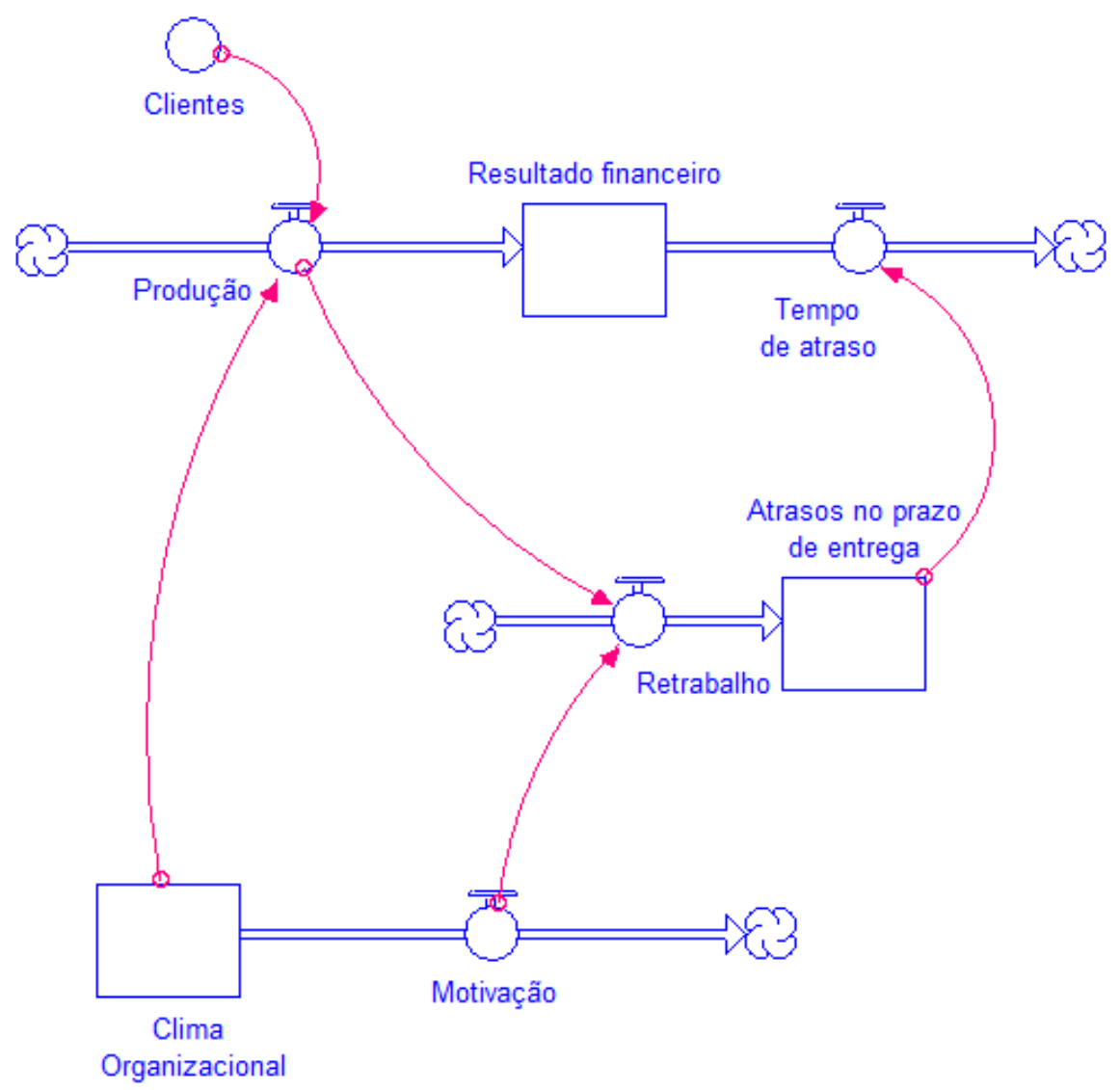

Fonte: Elaborado pelo autores

O estoque "Resultado financeiro" é incrementado por um fluxo de "Produção", que decorre de um auxiliar "Clientes", que por sua vez considera 100\% de clientes. Por outro lado, "Resultado financeiro" é decrementado pelo fluxo "Tempo de atraso". Essa Revista Produção Online, Florianópolis, SC, v. 16, n. 2, p. 408-440, abr./jun. 2016. 
variável possui ainda um valor inicial, que representa o valor financeiro inicial do orçamento empresarial, definido para simulação em 5000. Esse estoque é decrementado pelo fluxo "Tempo de atraso". Esse fluxo de saída considera integralmente os "Atrasos do prazo de entrega", conforme é possível identificar na seguinte expressão:

Resultado_financeiro $(t)=$ Resultado_financeiro $(t-d t)+(\text { Produção Tempo_de_atraso })^{\star} d t$ INIT Resultado_financeiro $=5000$

\section{INFLOWS:}

Produção = Clima_Organizacional+Clientes

\section{OUTFLOWS:}

Tempo_de_atraso $=$ Atrasos_no_prazo_de_entrega

Clientes $=100$

Na Figura 5 se encontra o resultado da simulação realizada no software STELLA 9.1.3 (ISEE SYSTEMS, 2009), considerando 12 interações que correspondem a doze meses ou um ano.

Figura 5 - Resultados da simulação do modelo de Dinâmica de Sistemas da Figura 4

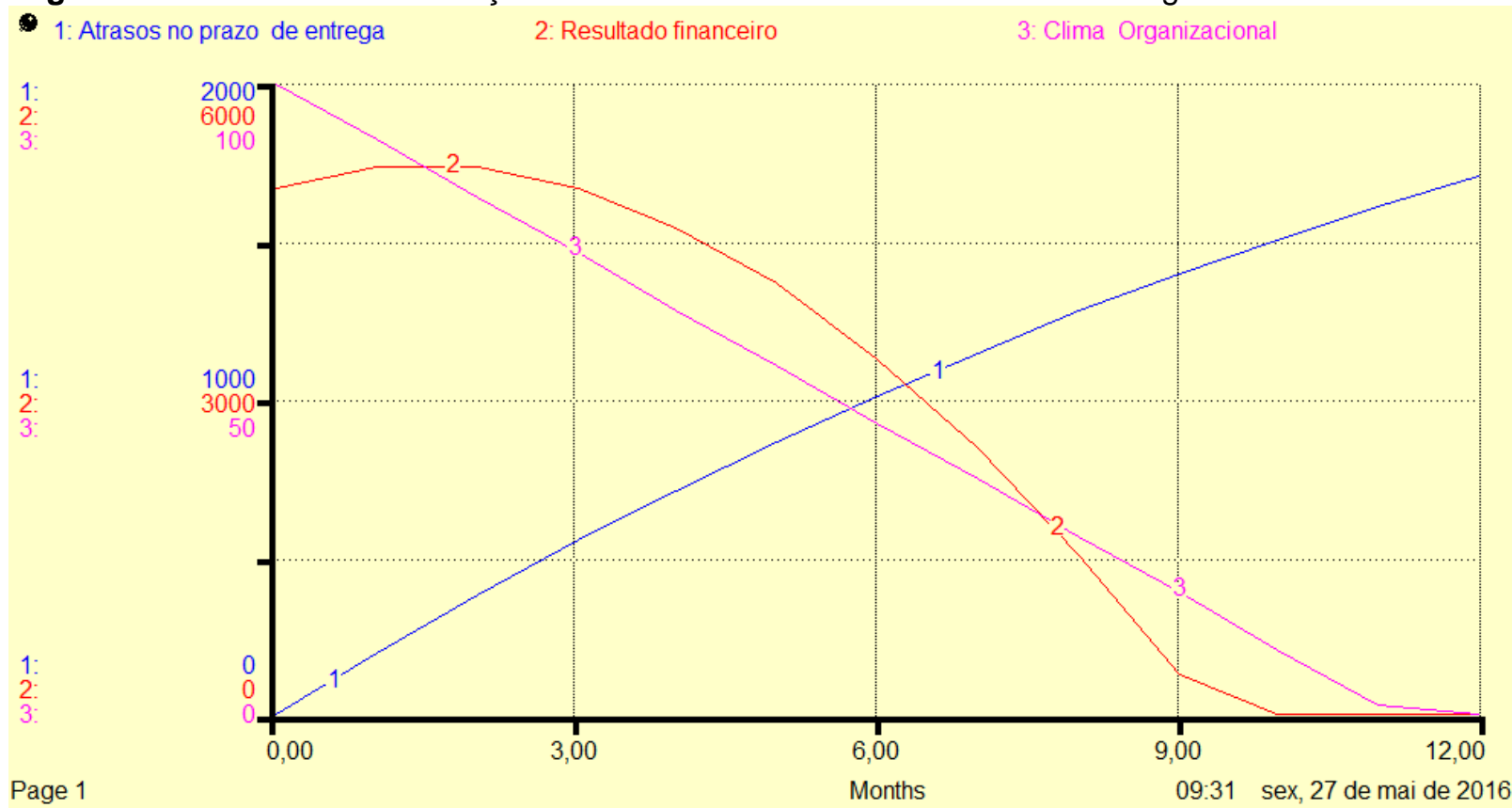

2日是?

Fonte: Elaborado pelo autores

Revista Produção Online, Florianópolis, SC, v. 16, n. 2, p. 408-440, abr./jun. 2016. 
A análise do gráfico da Figura 5 evidencia que a variável "Clima organizacional" tem um movimento descendente; já a variável "Atrasos no prazo de entrega" ascende. Como consequência disso, "Resultado financeiro" sobe em um primeiro momento, caindo posteriormente, até se extinguir no décimo mês de simulação. Os agentes validaram o movimento das curvas demonstradas como sendo, de fato, o padrão apresentado na realidade. A saída gráfica, que representa o modelo matemático de DS (hard), é a confirmação da modelagem realizada no mapa conceitual estendido (soft), que por sua vez, foi validada pelos agentes dos quais foi extraído o conhecimento.

Dessa maneira, o processo adotado foi capaz de identificar um problema desestruturado, submetê-lo a um processo de estruturação qualitativa (mapa conceitual estendido) e confirmá-lo dinamicamente por simulação, permitindo aos agentes aprenderem com a troca de informações existentes em seus modelos mentais particulares, criando um modelo mental compartilhado passivo de melhorias, imputadas de maneira conjunta.

\subsection{Estratégias de melhoria contínua e resultados obtidos}

As modelagens hard e soft permitem o desenvolvimento de uma análise mais abrangente, tornando possível projetar, em conjunto, ações que, segundo o juízo de valor dos agentes de decisão, possam resolver o problema existente no sistema complexo. Aos agentes foi possibilitada a criação de estratégias de melhoria contínua, por meio da análise do mapa conceitual estendido e do padrão gráfico obtido pela simulação. Essas estratégias consistiram na inclusão de três novos conceitos no mapa conceitual estendido, conforme demonstrado na Figura 6.

A Figura 6 demonstra a evolução do mapa conceitual estendido representado na Figura 3, e contém, além dos conceitos iniciais, também outras relações adicionadas pelos agentes, que possuem os seguintes significados:

- "Análise dos erros do projeto": se refere à ação de verificar, no final da produção, quais foram os erros do projeto, da produção e dos suprimentos;

Revista Produção Online, Florianópolis, SC, v. 16, n. 2, p. 408-440, abr./jun. 2016. 
- "Aprendizagem com os erros": uma vez evidenciados os erros, revela-se aquilo que é preciso mudar; as ações nessa fase são para corrigir projetos e alinhá-los ao resultado da fabricação;

- "Comunicação entre departamentos": demostra o entendimento do problema pelos agentes mediante sua comunicação com vistas à superação da situação problemática.

Cabe aqui lembrar que a compreensão do sistema auxilia a identificar suas debilidades, desassociando o indivíduo dos erros ocorrentes na ação, e contribuindo, portanto, para o processo de comunicação (SENGE, 2006).

Figura 6 - Mapa conceitual estendido com elementos de melhoria contínua

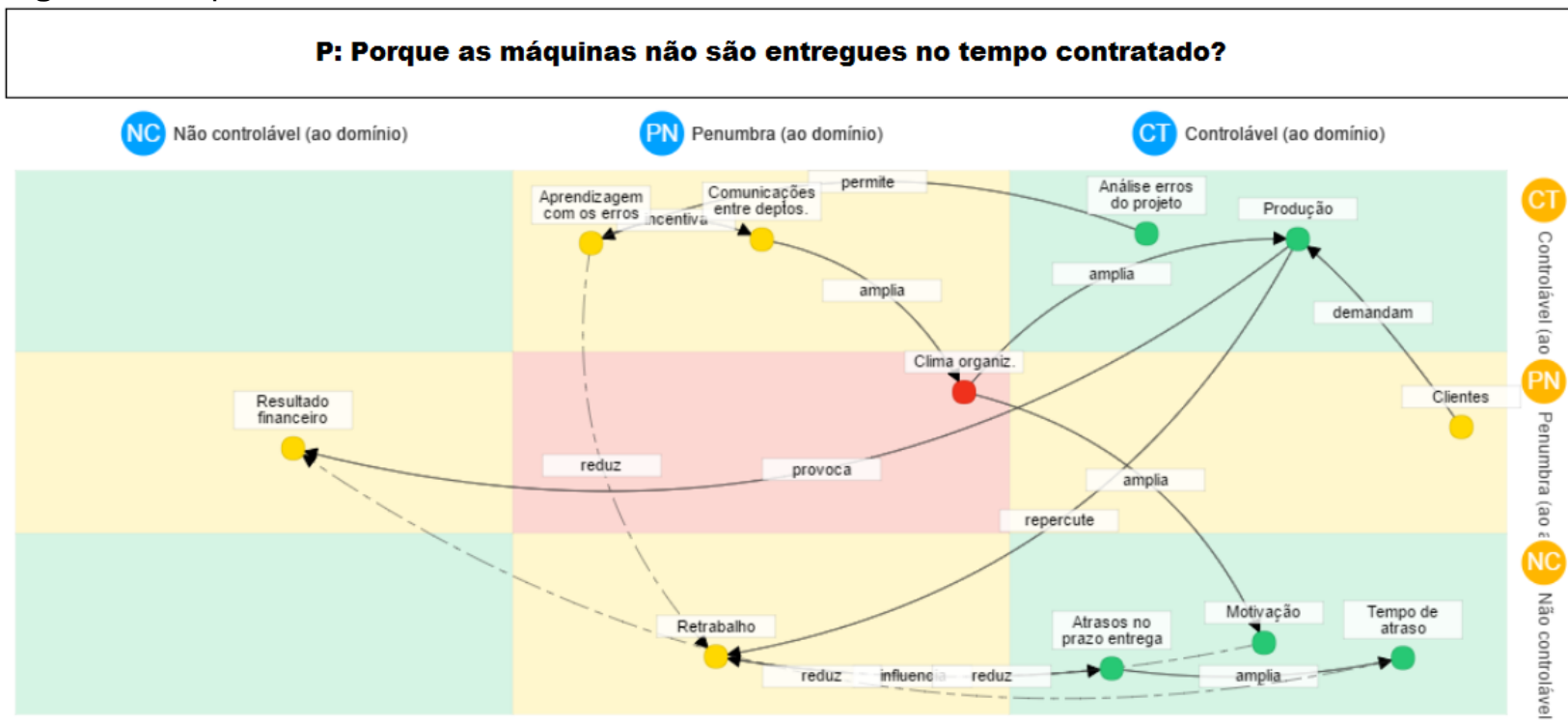

Fonte: Elaborado pelo autores

O conceito "Análise de erros do projeto" é controlável (CT) pelos agentes e representa um esforço determinante para mitigar o problema de entrega (CT). Desse conceito decorre a "Aprendizagem com erros", que provavelmente reforçará a redução de retrabalho (PN) incentivando a "Comunicação entre departamentos" (CT), que é tutorada pelos agentes e constitui, possivelmente, um fator de mudança (PN) no panorama das entregas. Espera-se que essa comunicação atue incrementando a mudança no 
"Clima organizacional". Entretanto, essa expectativa pode não ser atendida, pois esse conceito se situa em uma zona não controlável pelos agentes (NC, NC).

Concluída a análise soft da evolução do modelo mental dos agentes, faz-se a atualização do modelo simulado (hard), com o objetivo de testar a dinâmica das mudanças propostas e verificar se, de fato, podem refletir em uma alteração do quadro problemático. A Figura 7 mostra a evolução do modelo simulado por meio do diagrama de estoque e fluxo.

Figura 7 - Modelo de Dinâmica de Sistemas com melhoria contínua

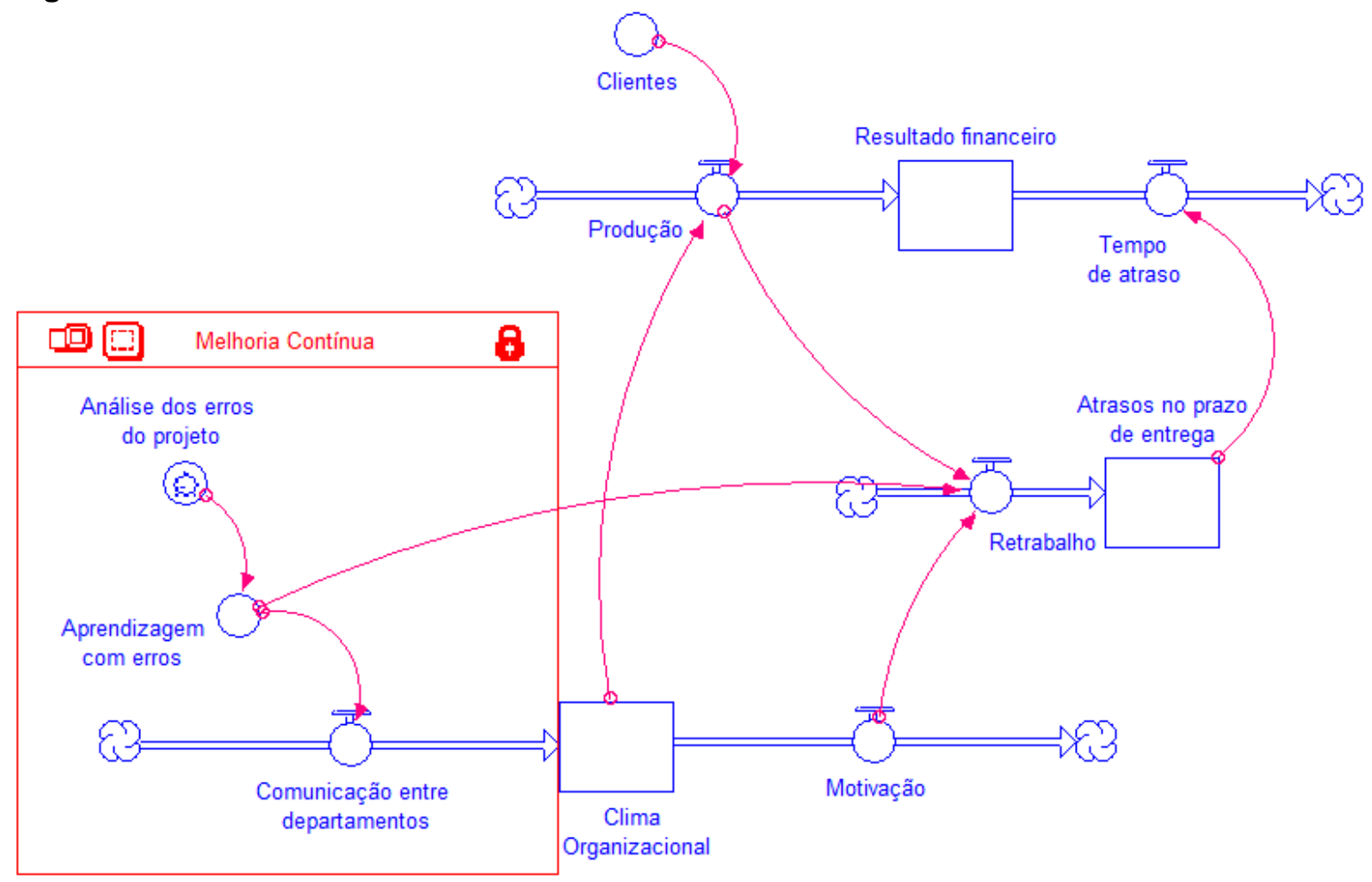

Fonte: Elaborado pelo autores

O conceito "Comunicação entre departamentos" é um fluxo que incrementa o estoque "Clima organizacional" com o valor advindo de "Aprendizagem com erros", que por sua vez, possui uma taxa de entrada de 0, 5, 10 ou 15 erros, dependendo da "Análise de erros do projeto". A seguinte expressão demonstra essas novas relações:

Comunicação_entre_departamentos = Aprendizagem_com_erros

Revista Produção Online, Florianópolis, SC, v. 16, n. 2, p. 408-440, abr./jun. 2016. 
Analise_dos_erros_do_projeto $=0 ; 5 ; 10 ; 15$

Aprendizagem_com_erros $=$ Analise_dos_erros_do_projeto

Esse novo input do modelo permite variar a quantidade de erros criando a oportunidade de simulações em diferentes cenários. Foram realizadas simulações em quatro cenários:

- zero erros: ausência de análise de erros, onde se constata o problema inicial;

- cinco erros: indica uma análise de erros no início da implantação;

- dez erros: estágio superior de análise onde já existe aprendizado anterior;

- quinze erros: equivale à totalidade das análises feitas.

As Figuras de número 8 a 10 demonstram os resultados das mudanças nas variáveis estoque nos diferentes cenários, considerando cem (100) interações, que equivalem a cem (100) meses.

A Figura 8 representa a variável "Atrasos no prazo de entrega". Observa-se que no cenário um, essa variável demonstrou uma forte tendência de subida, idêntica às situações problemáticas simuladas sem as ações de melhoria contínua. No cenário dois, que indica o início da análise dos erros, o prazo de entrega tende a aumentar. Esse fato pode ser explicado devido à demora na análise dos erros que agora faz parte do processo empresarial. Se esse fato fosse analisado isoladamente, poderia representar um fator de desmotivação para os agentes, levando-os a abandonar a estratégia de melhoria contínua. Entretanto, pela análise sistêmica obtida por meio da simulação, é evidente que essa é uma situação necessária e passageira, que trará resultados no futuro. 
Figura 8 - Resultados da simulação da variável "Atrasos no prazo de entrega"

- Atrasos no prazo de entrega: 1 - 2 - 3 - 4 -

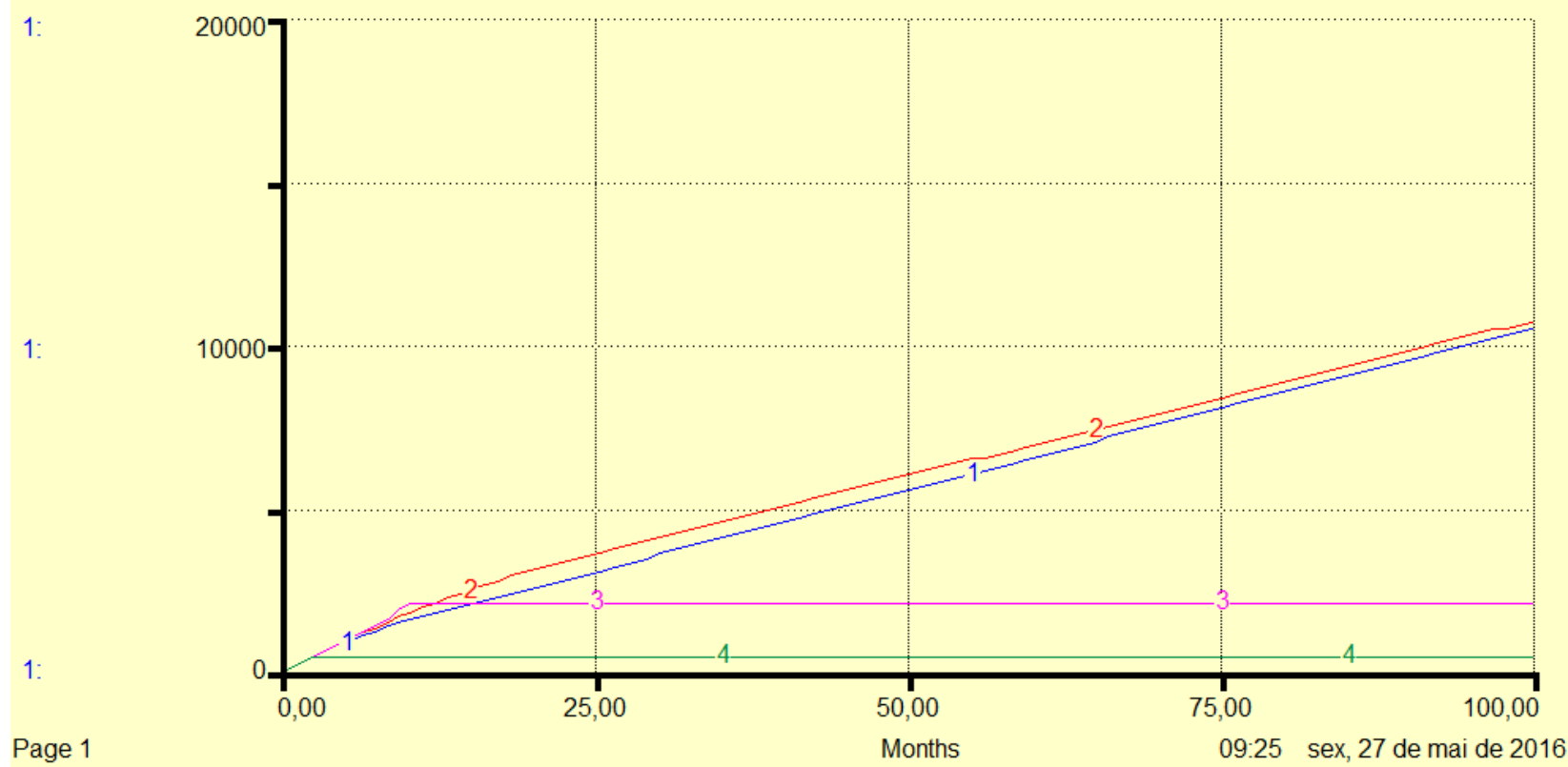

昌米?

Fonte: Elaborado pelo autores

Observa-se ainda na Figura 8 o momento em que os projetos com análises de erros começam a ser usados na produção (cenário três). Sem a necessidade de passar por um novo projeto, o prazo de entrega tende a se equilibrar, eliminando a tendência ao crescimento. No cenário quatro, o prazo de entrega é menor ainda, pois praticamente todas as máquinas já tiveram seus projetos analisados, diminuindo, desse modo, o trabalho dos projetistas.

A Figura 9 representa a variável "Clima organizacional", inserida em quatro cenários diferentes.

É possível observar que no cenário um da Figura 9, existe uma taxa decrescente da variável "Clima organizacional"; no segundo cenário existe uma melhoria dessa variável, porém a taxa ainda é decrescente. Somente no terceiro cenário o clima tende a se equilibrar com uma pequena taxa crescente e, por fim, no quarto cenário, o clima se mostra positivo.

Revista Produção Online, Florianópolis, SC, v. 16, n. 2, p. 408-440, abr./jun. 2016. 
Figura 9 - Resultados da simulação da variável "Clima organizacional"

- Clima Organizacional: 1-2-3-4-

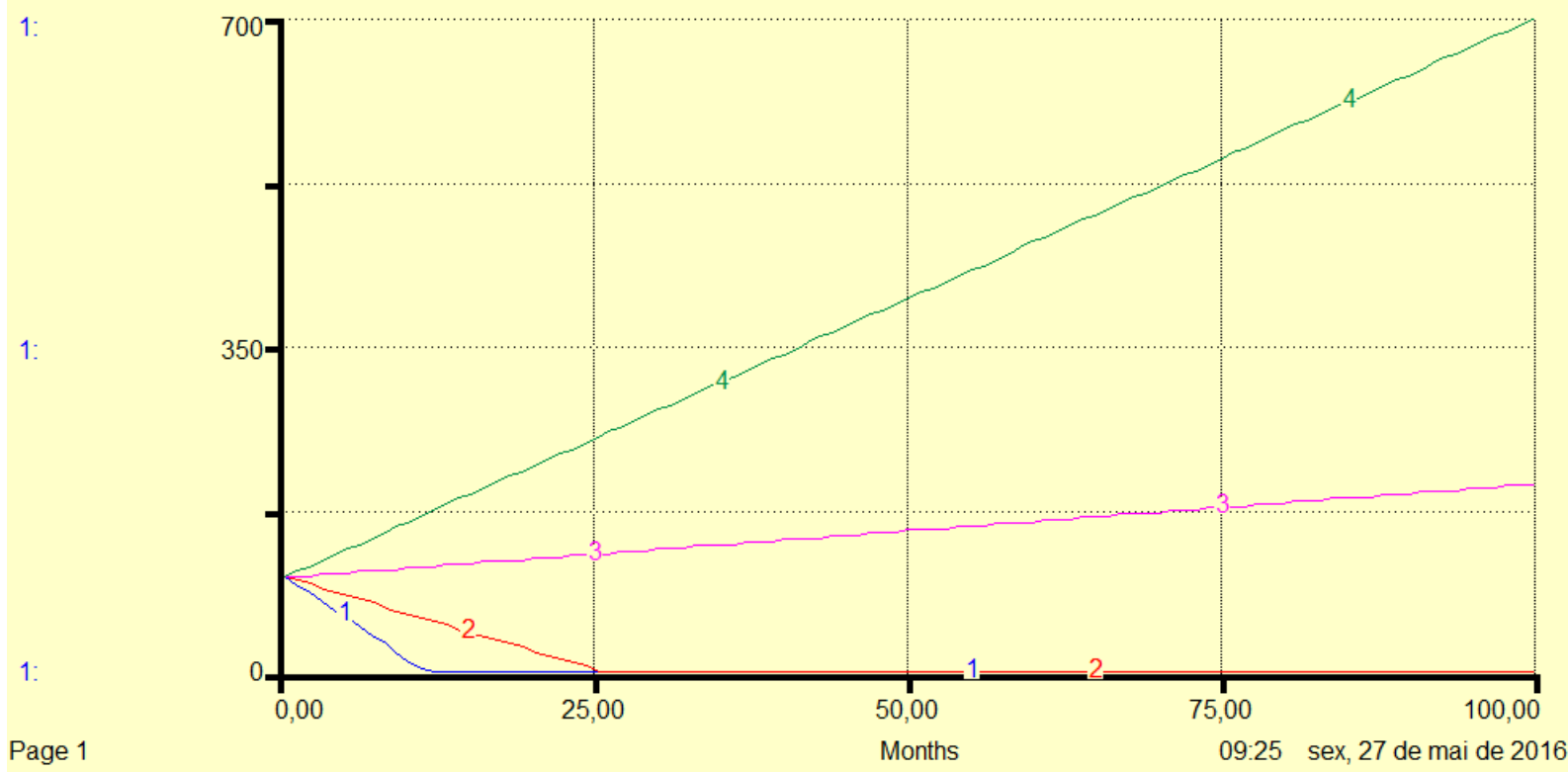

a昌綮?

Fonte: Elaborado pelo autores

A Figura 10 demonstra os quatro cenários da variável "Resultado da empresa".

Figura 10 - Resultados da simulação da variável "Resultado financeiro"

- Resultado financeiro: 1 - 2-3-4 -

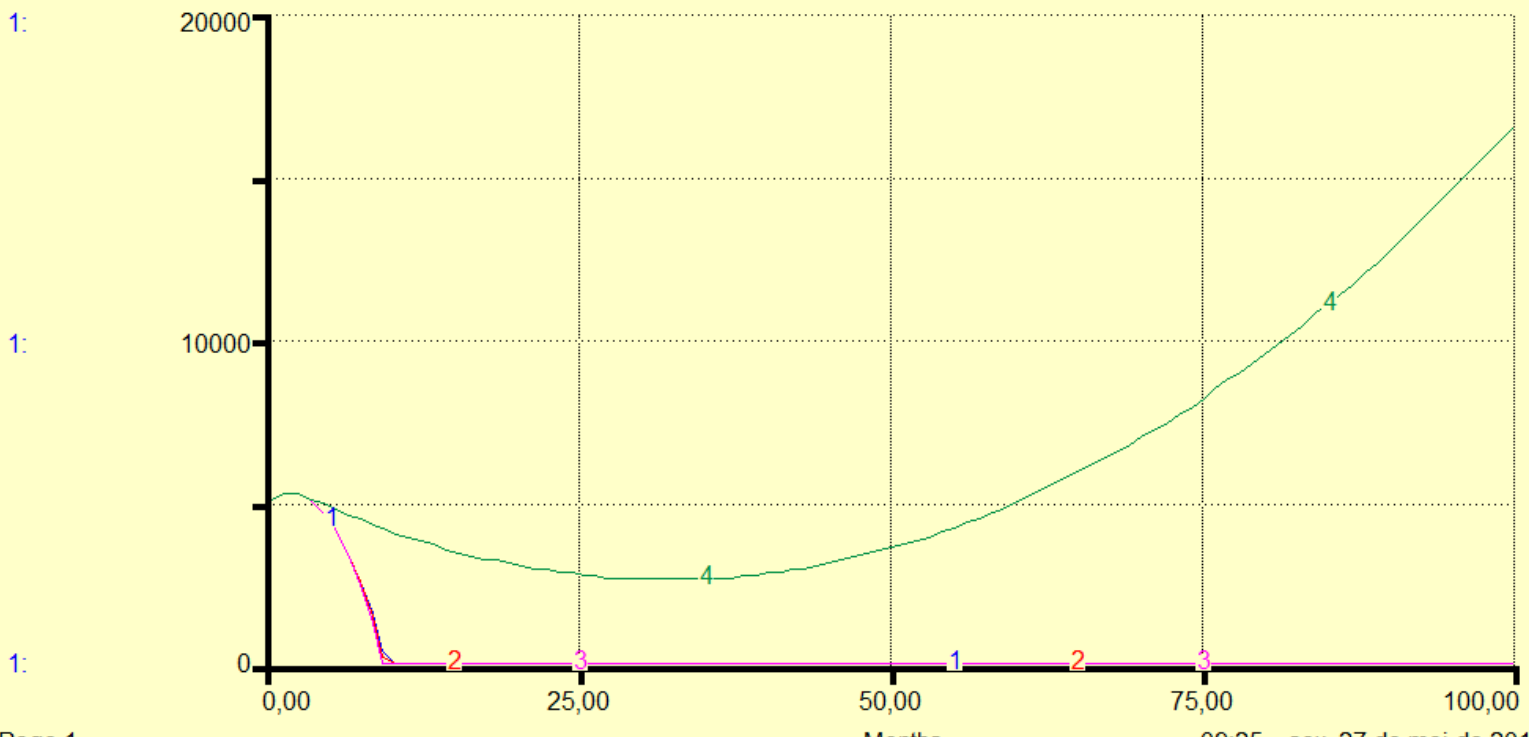

Page 1

Months

09:25 sex, 27 de mai de 2016

a昌米?

Fonte: Elaborado pelo autores

Revista Produção Online, Florianópolis, SC, v. 16, n. 2, p. 408-440, abr./jun. 2016. 
Observa-se na Figura 10 que os cenários um, dois e três não são satisfatórios, pois correspondem à situação da empresa sem as ações de melhoria contínua. Apenas no quarto cenário, onde as ações de análise dos erros, aprendizado e comunicação estão em um estágio mais maduro é que o lucro aparece, inicialmente com taxa decrescente até o trigésimo mês de simulação e, depois, com uma taxa exponencial de crescimento.

\section{CONCLUSÃO}

Este artigo apresentou um modelo de solução de problemas apoiado em mapas conceituais estendidos e simulação em Dinâmica de Sistemas, com o objetivo de atender a um problema situado na fronteira entre a abordagem estruturada e não estruturada.

O problema analisado foi observado em uma pequena empresa familiar produtora de máquinas e se manifestava na dificuldade dessa empresa em entregar os pedidos de vendas nos prazos previamente combinados com seus clientes. Esse problema era acompanhado pela discordância entre os gestores com relação ao processo mais adequado para se gerenciar a crise, fato que degradava o clima organizacional.

Para a estruturação do problema foi utilizado um mapa conceitual estendido (ZAMBON; BAIOCO; MAGRIN, 2012), que originou um modelo de simulação baseado em DS (FORRESTER, 1980; SENGE, 2006), com o objetivo de testar a dinâmica do ambiente problemático.

Por meio dessa modelagem foi possível demonstrar que problemas de fronteira são complexos e demandam soluções compostas por diferentes estratégias que se complementam. O mapa conceitual estendido mostrou ser capaz de promover aprendizagem em grupo e servir de base para a construção de um modelo simulado, o qual permitiu a visualização da dinâmica dos diferentes cenários para a solução do problema. Dessa maneira, foi possível para os gestores compreenderem a dinâmica das mudanças planejadas.

Revista Produção Online, Florianópolis, SC, v. 16, n. 2, p. 408-440, abr./jun. 2016. 
Após a aplicação das alternativas propostas e aceitas pelos gestores, foram observadas mudanças efetivas no sistema real. Essas mudanças desencadearam alterações no comportamento gerencial, melhorando o clima organizacional, que se manteve em um padrão satisfatório nos meses subsequentes ao início das mudanças. Essa alteração no relacionamento entre os gestores permitiu o entendimento de como ações qualitativas decididas em conjunto convergem para a ampliação da confiança e do clima organizacional.

Verifica-se, desse modo, que instrumentos apoiados em gestão do conhecimento, com foco nos processos cognitivos dos agentes, podem provocar alterações sustentáveis no sistema, em razão de agirem sobre o aprendizado coletivo. A associação a instrumentos de simulação fecha o ciclo de aprendizagem, pois permite aos agentes projetarem e visualizarem os resultados futuros.

Comparativamente à iniciativa de Rodriguez-Ulloa (2005), foi demonstrado que a utilização de instrumentos soft, com foco em gestão do conhecimento, possibilita aos analistas aprofundar suas análises e gerar aprendizagem organizacional, provocando melhorias na capacidade do trabalho em grupo e tornando-as sustentáveis no sistema empresarial.

Conclui-se que ferramentas de gestão do conhecimento aplicadas em conjunto com modelagem e simulação podem auxiliar no entendimento da estrutura do sistema complexo empresarial, mostrando-se importantes aliadas para a gestão de problemas em áreas de fronteira.

\section{REFERÊNCIAS}

ARGOTE, Linda. Organizational learning: creating, retaining and transferring knowledge. Springer, 2012. http://dx.doi.org/10.1007/978-1-4614-5251-5

BADDELEY, Alan. Working Memory Alan Baddeley. Science, v. 255, n. 5044, p. 556$559,1992$.

Revista Produção Online, Florianópolis, SC, v. 16, n. 2, p. 408-440, abr./jun. 2016. 
BERTALANFFY, Ludwig V. Teoria geral dos sistemas: fundamentos, desenvolvimentos e aplicações. São Paulo: Vozes, 2008 .

BEUREN, Marcelo M.; FRANK, Alejandro G.; RIBEIRO, José L. D. Análise da transferência de conhecimento em projetos na indústria petroquímica. Revista Produção Online, v. 15, n. 1, p. 213-242, 2015. http://dx.doi.org/10.14488/1676-1901.v15i1.1759

CERRATO, Daniele; PIVA, Maria cristina. The internationalization of small and mediumsized enterprises: the effect of family management, human capital and foreign ownership. Journal of Management \& Governance, 2012, 16.4: 617-644. http://dx.doi.org/10.1007/s10997-010-9166-x

CEZARINO, Luciana O.; BELTRÁN, Aníbal C. Diagnosis of organizational soft problems in a Peruvian financial institution by systemic thinking. Systemic Practice and Action Research, v. 22, n. 2, p. 101-110, 2009. http://dx.doi.org/10.1007/s11213-008-9115-7

CHECKLAND, Peter B. Information systems and systems thinking: time to unite?. International Journal of Information Management, v. 8, n. 4, p. 239-248, 1988.

http://dx.doi.org/10.1016/0268-4012(88)90031-X

FLOOD, Robert L.; JACKSON, Michael C. Total systems intervention: a practical face to critical systems thinking. Systems Practice, v. 4, n. 3, p. 197-213, 1991.

http://dx.doi.org/10.1007/BF01059565

FLOOD, Robert L.; CARSON, Ewart. Dealing with complexity: an introduction to the theory and application of systems science. Springer Science \& Business Media, 2013.

FORRESTER, Jay. W. Industrial dynamics. New York: John Wiley \& Sons, 1980. FRANK, Alejandro G.; ECHEVESTE, Márcia E. Barreiras de transferência de conhecimentos entre projetos de produtos. Revista Produção Online, v. 11, n. 1, p. 29-53, 2011. http://dx.doi.org/10.14488/1676-1901.v11i1.389

GARCÍA-MORALES, Víctor Jesús; JIMÉNEZ-BARRIONUEVO, María Magdalena; GUTIÉRREZ-GUTIÉRREZ, Leopoldo. Transformational leadership influence on organizational performance through organizational learning and innovation. Journal of Business Research, 2012, 65.7: 1040-1050.

GENTNER, Dedre; STEVENS, Albert L. Mental models. Psychology Press, 2014.

GUASCO, Matthew; ROBINSON, Peter R. Principles of negotiation: strategies, tactics, techniques to reach agreement. Entrepreneur Press, 2007. 
GUPTA, Atul; HAMMOND, Rex. Information systems security issues and decisions for small businesses: an empirical examination. Information Management \& Computer Security, v. 13, n.4, p. 297-310, 2005. http://dx.doi.org/10.1108/09685220510614425

HAKEN, Hermann. Information and self-organization: a macroscopic approach to complex systems. Springer, 2006.

HILL, Charles; JONES, Gareth; SCHILLING, Melissa. Strategic management: theory: an integrated approach. Cengage Learning, 2014.

HUMPHREYS, Kerry A. Dynamic decision making using the balanced scorecard. Tese de Doutorado. School of Business University of New South Wales Michael Shayne, October 2013.

ISEE SYSTEMS. STELLA software. v. 9.1.3 for Windows. USA: Isee systems, 2009. Disponível em: <http://www.iseesystems.com>. Acesso em 05 out. 2013.

JOHNSON-LAIRD, Philip N. 8 The history of mental models. Psychology of reasoning: Theoretical and historical perspectives, p. 179, 2004.

KRAMER, Nic JTA; DE SMIT, Jacob. Systems thinking: Concepts and notions. Springer Science \& Business Media, 2012. http://dx.doi.org/10.1007/978-1-4613-4229-8

KIMMERLE, Joachim; CRESS, Ulrike; HELD, Christoph. The interplay between individual and collective knowledge: technologies for organizational learning and knowledge building. Knowledge Management Research \& Practice, v.8, n. 1, p. 33-44, 2010. http://dx.doi.org/10.1057/kmrp.2009.36

LEVINE, John M.; THOMPSON, Leigh L.; MESSICK, David M. Shared cognition in organizations: The management of knowledge. Psychology Press, 2013.

LIEBOWITZ, Jay; FRANK, Michael (Ed.). Knowledge Management and E-learning. CRC Press, 2010. http://dx.doi.org/10.1201/b10347 LUNARDI, Guilherme L.; DOLCI, Pietro C.; MAÇADA, Antônio C. G. Adoção de tecnologia de informação e seu impacto no desempenho organizacional: um estudo realizado com micro e pequenas empresas. R. Adm., v.45, n.1, p.05-17, jan./fev./mar. 2010.

MALAQUIAS, Rodrigo F.; ALBERTIN, Alberto L. Por que os gestores postergam investimentos em tecnologia da informação? um estudo de caso. RAC-Revista de Administração Contemporânea, v. 15, n. 6, p. 1120-1136, 2011.

MORECROFT, John D. W.; STERMAN, John D. (Ed.). Modeling for learning organizations. Productivity Press, 2000.

Revista Produção Online, Florianópolis, SC, v. 16, n. 2, p. 408-440, abr./jun. 2016. 
MORECROFT, John D. W. Strategic modelling and business dynamics: A feedback systems approach. John Wiley \& Sons, 2015.

http://dx.doi.org/10.1002/9781119176831

MOSCOSO, Philip G.; FRANSOO, Jan C.; FISCHER, Dieter. An empirical study on reducing planning instability in hierarchical planning systems. Production Planning and Control, v. 21, n. 4, p. 413-426, 2010. http://dx.doi.org/10.1080/09537280903454172

NONAKA, Ikujiro; TAKEUCHI, Hirotaka. The Knowledge-creating Company: how Japanese companies create the Dynamics of Innovation. Long range planning, v. 29, n. 4, p. 592, 1996. http://dx.doi.org/10.1016/0024-6301(96)81509-3

NORTH, Klaus. Gestão do conhecimento um guia prático rumo à empresa inteligente. Rio de Janeiro: QualityMark, 2010.

OU, Amy Y., et al. Humble chief executive officers' connections to top management team integration and middle managers' responses. Administrative Science Quarterly, 2014, 0001839213520131.

RODRIGUEZ-ULLOA, Ricardo; PAUCAR-CACERES, Alberto. Soft system dynamics methodology (SSDM): combining soft systems methodology (SSM) and system dynamics (SD). Systemic Practice and Action Research, v. 18, n. 3, p. 303-334, 2005. http://dx.doi.org/10.1007/s11213-005-4816-7

SEBRAE. Anuário do trabalho na micro e pequena empresa. 5. ed. Brasília, DF; DIEESE, 2012. Disponível em: <http://goo.gl/eHX1sd>. Acesso em 20 abr. 2013.

SENGE, Peter M. The fifth discipline: the art and practice of the learnig organization. Revisited ed. New York: Doubleday, 2006.

STERMAN, John D. Business dynamics: systems thinking and modeling for a complex world. New York: McGraw-Hill, 2000.

TACHIZAWA, Takeshy. Gestão com pessoas: uma abordagem aplicada às estratégias de negócios. Editora FGV, 2015.

VASQUES, Dildre G.; ZAMBON, Antonio C.; BAIOCO, Gisele B.; MARTINS, Paulo S. An Approach to Knowledge Acquisition Based on Verbal Semantics. In: 2016 49th Hawaii International Conference on System Sciences (HICSS). IEEE, 2016. p. 41444153. http://doi.org/10.1109/HICSS.2016.514

ZAMBON, Antonio C.; BAIOCO, Gisele B.; MAGRIN, Diego H. MORPH - Modelo Orientado à Representação do Pensamento Humano. In: Congresso Latino-americano de

Revista Produção Online, Florianópolis, SC, v. 16, n. 2, p. 408-440, abr./jun. 2016. 
Dinâmica de Sistemas 2012, Buenos Aires. Anais do X Congresso Latino-americano de dinâmica de Sistemas. Buenos Aires, 2012.

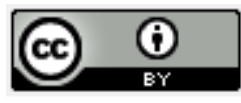

Artigo recebido em 14/05/2014 e aceito para publicação em 17/05/2016

DOI: http://dx.doi.org/ 10.14488/1676-1901.v16i1.1799

Revista Produção Online, Florianópolis, SC, v. 16, n. 2, p. 408-440, abr./jun. 2016. 